\title{
"Muro baixo, o povo pula": iniciativas institucionais de participação digital e seus desafios fundamentais
}

\author{
Francisco Paulo Jamil Almeida Marques \\ Departamento de Comunicação Social \\ Universidade Federal do Maranhão
}

\begin{abstract}
Resumo: $O$ artigo investiga as dificuldades mais comuns enfrentadas pelos projetos governamentais voltados para incrementar a participação através do emprego dos media digitais. Após breve diagnóstico dos recursos participativos existentes nos Portais da Presidência da República e da Câmara dos Deputados, é verificado se os constrangimentos técnicos e políticos que a literatura aponta em relação à adoção das ferramentas de comunicação digital se refletem em tais experiências. À luz dos elementos fornecidos pela investigação dos casos empíricos, defende-se o argumento de que promover a participação requer mais do que a oferta de recursos de comunicação, uma vez que cultura cívica e outras peculiaridades de cada democracia são fatores determinantes a influenciarem os padrões de envolvimento político. Se a idéia dos autores mais eufóricos se refere ao argumento de que a Internet torna o "muro" que protege as instituições representativas mais fácil de pular, deve-se considerar que o jogo político tradicional conta, muitas vezes, com artifícios próprios a fim de evitar o emprego efetivo das capacidades da rede digital.
\end{abstract}

Palavras-Chave: internet; democracia; participação; instituições políticas; representação

Abstract: The article examines the difficulties faced by government projects aimed at fostering citizens' political participation by using the Internet. After presenting the participatory tools found on two institutional websites (the Brazilian Presidency and the House of Representatives), I examine how the constraints pointed out by a relevant part of the literature in e-participation are reflected on such initiatives. The discussion grounded on empirical evidences highlights the argument that promoting online participation needs more than providing communication resources, since civic culture and other issues are still key factors in influencing our patterns of political involvement. A participatory use of digital tools will then depend more on circumstances such as institutional willingness than on the technical mechanisms available.

Keywords: e-democracy; e-government; political participation; political institutions

OPINIÃO PÚBLICA, Campinas, vol. 16, no 1, Junho, 2010, p. 117-142 


\section{Introdução ${ }^{1}$}

Uma importante parte das pesquisas em democracia digital realizada na última década ainda enfatiza as supostas vantagens trazidas pela Internet ao campo da política (BUCY \& GREGSON, 2000; DELLI CARPINI, 2000; COLEMAN \& GØTZE, 2001; BOHMAN, 2004; FROOMKIM, 2004; STANLEY \& WEARE, 2004; GUEORGUIEVA, 2007). Especificamente no que se refere à questão da participação política dos cidadãos, um argumento comum é o de que obstáculos técnicos e outras dificuldades atinentes à promoção do envolvimento político podem ser reduzidos uma vez que os recursos digitais sejam empregados. Por exemplo, afirma-se haver uma variedade de caminhos para se tornar a participação mais fácil, conveniente e ágil por meio da promoção de consultas públicas, da criação de fóruns de discussão ou do fortalecimento da atuação em rede de movimentos sociais (MITRA, 2001; BENNETT, 2003; MARCHE \& MCNIVEN, 2003; SALTER, 2003; SCHUSSMAN \& EARL, 2004; GIBSON, LUSOLI \& WARD, 2005; MARMURA, 2008).

Por outro lado, há estudiosos prontos a desafiar tal associação positiva entre o uso dos media digitais e o aperfeiçoamento das práticas democráticas. Dentre os principais problemas identificados estão a exclusão digital, a baixa qualidade da informação política disponível para aqueles que têm acesso aos new media, a crescente tendência comercial da Internet e as ameaças à liberdade e à privacidade que os usuários costumeiramente enfrentam (CARLSON \& DJUPSUND, 2001; DREYFUS, 2001; NORRIS, 2001; DEAN, 2003; GUNKEL, 2003; DAHLBERG, 2005; SEIFERT \& CHUNG, 2009). Além disso, alguns dos pesquisadores mais céticos argumentam que a Internet prejudicaria a esfera pública por conta da possibilidade de fragmentação do discurso público. De acordo com tais autores, os usuários tenderiam a perder interesse em discutir temas de concernência comum uma vez que eles podem, voluntariamente, escolher a natureza das informações que recebem; ademais, sugere-se que as ferramentas digitais podem ser empregadas para fortalecer a organização de grupos avessos aos debates ou, no limite, ao respeito às diferenças (WOLTON, 2001; STROMER-GALLEY, 2000; SUNSTEIN, 2001; SCHEUFELE \& NISBET, 2002; COLEMAN \& SPILLER, 2003; SHULMAN, 2004; HOOGHE \& TEEPE, 2005; DAHLBERG, 2007).

A discussão sobre os benefícios ou as desvantagens de se usar a Internet para aperfeiçoar a democracia permanece importante hoje em dia. Contudo, a fim

1 O autor é Pós-Doutor em Comunicação Social pela UFMG e agradece à Capes e ao CNPq pelo financiamento à pesquisa ao longo de seu Doutorado e Pós-Doutorado (PRODOC). $\mathrm{O}$ autor agradece aos pareceristas anônimos da Revista Opinião Pública pelas críticas e sugestões fundamentais feitas ao artigo. 
de investigar que tipos de modificações os new media trazem, de fato, para o campo político, é preciso ir além da síntese do potencial e dos limites da comunicação digital.

Assim sendo, neste artigo pretende-se, especificamente, discutir quais são os principais fatores a influenciar o modo como as instituições políticas tornam disponíveis ferramentas voltadas para fortalecer o envolvimento político dos cidadãos. Por acreditar que a simples existência técnica de ferramentas digitais não garante que estes mecanismos estejam sendo adotados de forma a promover maiores e melhores oportunidades de participação política, considera-se importante compreender aquelas razões que se encontram por trás das decisões governamentais no que se refere à participação online. Quais são os custos envolvidos uma vez que o governo oferece ferramentas de participação digital? Quais são as principais razões que condicionam a disposição (ou a indisposição) dos representantes em interagir com os cidadãos? De que modo os custos (financeiros e políticos) estão refletidos no desenho das ferramentas participativas? A fim de responder a estas questões, o seguinte artigo apresenta alguns dos resultados de uma pesquisa cujo principal objetivo foi examinar os meios e modos através dos quais duas instituições políticas do Estado brasileiro - a Câmara dos Deputados e a Presidência da República - oferecem aos cidadãos oportunidades de participação política através da Internet ${ }^{2}$ (MARQUES, 2008).

Estas duas experiências foram estudadas levando-se em consideração os seguintes passos metodológicos: conduziu-se uma análise de documentos na intenção de se apreender o contexto da política de democracia digital adotada por cada uma destas instituições (os princípios oficiais que guiam os modos pelos quais ambos websites foram configurados foram examinados cuidadosamente, a fim de se comparar (a) propósitos descritos "no papel" com os (b) usos práticos); entrevistas com os responsáveis que trabalham na administração de cada uma destas iniciativas (a meta foi entender suas perspectivas acerca de participação digital, bem como revelar de que forma tais instituições configuram ferramentas e processam os inputs originados a partir da interação com os usuários); acessos monitorados aos websites, realizados entre Setembro de 2007 e Abril de 2008, conferindo-se atenção especial às características e ao uso dos recursos participativos disponíveis nos websites.

A este ponto, deve-se ressaltar que a seção empírica desenvolvida neste presente trabalho é, essencialmente, um exercício de análise qualitativa. Tabelas,

\footnotetext{
2 Como justificativa para a escolha destas duas instituições, aponta-se a importância delas na estrutura do Estado brasileiro e a influência que a Presidência e a Câmara exercem sobre outros níveis administrativos governamentais no país.
} 
cálculos e outros instrumentos quantitativos são fundamentais para se verificar fenômenos tais como os modos pelos quais os cidadãos usam os mecanismos digitais (e aqui se reconhece que não usar tal estratégia quantitativa pode colocar alguns dos achados em risco). Entretanto, acredita-se que uma pesquisa qualitativa é a melhor opção para se compreender alguns dos fatores que influenciam as iniciativas de participação digital. Apenas um estudo interpretativo daquelas atitudes e políticas registradas em documentos e captadas nas entrevistas parece ser adequado para se oferecer resposta para algumas das perguntas acima apontadas ${ }^{3}$.

Em sua primeira parte, o artigo apresenta um breve diagnóstico das ferramentas participativas encontrada no Portal da Presidência (http://www.presidencia.gov.br/) o no Portal da Câmara dos Deputados (http://www.camara.gov.br/). Em seguida, são discutidas as principais dificuldades (identificadas por um grupo relevante de pesquisadores) que as instituições ligadas ao Estado enfrentam uma vez que adotam as tecnologias digitais com a finalidade de incrementar as práticas participativas. O terceiro tópico examina em que medida as dificuldades e desafios previamente discutidos se refletem nos dois casos empíricos selecionados para compor a pesquisa. Finalmente, considera-se um outro conjunto de problemas que se impõe sobre a maioria das iniciativas institucionais voltadas para se aperfeiçoar a participação política: enfatiza-se a idéia de que as regras tradicionais do jogo democrático continuam a influenciar, de forma notável, os projetos de democracia digital.

\section{Mapeamento das ferramentas de participação digital em websites institucionais: duas experiências brasileiras}

Sabe-se que o Brasil é uma das maiores democracias do mundo. O voto obrigatório leva cerca de 120 milhões de cidadãos às urnas a cada dois anos. Desde a aprovação da Constituição de 1988, o país vem se mostrando um dos mais proeminentes no que se refere a incentivar o envolvimento político dos cidadãos: é nesse sentido que o orçamento participativo ou os conselhos de políticas têm chamado a atenção de um grande número de estudiosos (KECK, 1995; ABERS, 2001; BAIOCCHI, 2005; FUNG \& WRIGHT, 2001; AVRITZER, 2009; WAMPLER, 2009).

Além disso, o Brasil possui um contingente numeroso de usuários das redes telemáticas. De fato, uma série de pesquisas aponta que os brasileiros gastam mais

\footnotetext{
${ }^{3} \mathrm{E}$ aqui podem ser mencionados alguns trabalhos que têm uma perspective similar considerando a importância de abordagens qualitativas para o estudo da internet: Franklin \& Lowry, 2001; OECD, 2003; Medaglia, 2007; Thorsen, 2008.
} 
tempo conectados à Internet do que qualquer outro povo. Cerca de $80 \%$ dos usuários de Internet do país possuem um perfil em alguma rede social, como, por exemplo, o Orkut ou o Facebook ${ }^{4}$. Tal fenômeno torna o Brasil um dos líderes no ranking de uso das tecnologias digitais de comunicação e esta é, provavelmente, uma das principais razões pelas quais ele vem sendo regularmente mencionado em vários artigos e relatórios nacionais e internacionais a destacarem as inovações em democracia digital (GIBSON, 2001; NORRIS, 2001; NETCHAEVA, 2002; BALNAVES, WALSH \& SHOESMITH, 2004; UNITED NATIONS, 2005 e 2008).

Tendo tal contexto em mente, a parte empírica da pesquisa mais ampla que gerou este artigo (MARQUES, 2008) examinou dois websites institucionais brasileiros, a saber, o Portal da Câmara dos Deputados e o Portal da Presidência da República, do seguinte modo: primeiramente, descreveu-se, de forma breve, a trajetória dos modos de adoção das tecnologias digitais por parte de tais instituições; em seguida, foram apresentadas as principais diretrizes oficiais a orientarem o emprego dos recursos digitais de comunicação no âmbito das duas entidades; logo depois, as ferramentas participativas encontradas em ambos websites foram analisadas levando-se em consideração os seguintes aspectos: a capacidade de prover informações e de fortalecer o cultivo de habilidades políticas por parte dos cidadãos; o grau de estímulo e motivação dado aos usuários para que se envolvam politicamente; a variedade e a profundidade dos mecanismos de participação presentes nas iniciativas em tela (VERBA SCHLOZMAN \& BRADY, 1995; DELLI CARPINI, 2000; CREIGHTON, 2005).

Um segundo passo reflexivo da pesquisa desta mais ampla investigou, especificamente, duas outras questões: (a) os efeitos políticos que as ferramentas tecnicamente disponíveis podem gerar sobre o processo institucional de produção da decisão política; (b) os constrangimentos e as dificuldades apontados por uma parte relevante da literatura em e-participação e como tais obstáculos se refletem sobre as iniciativas selecionadas para análise. Por último, a pesquisa mais aprofundada se preocupou em fazer sugestões a fim de aperfeiçoar as experiências já em andamento no âmbito do Estado brasileiro.

Obviamente, não é possível apresentar, em um único artigo, as descobertas trazidas por uma pesquisa empírica de maior escopo. No entanto, é possível provar que estes websites empregam as ferramentas digitais de forma bastante díspar, apontando as possíveis causas a provocarem tal fenômeno.

Dentre os resultados da pesquisa ampliada (MARQUES, 2008), apontou-se que o Portal da Presidência enfatiza, preponderantemente, o provimento de

\footnotetext{
${ }^{4}$ Para mais informações, <http://www1.folha.uol.com.br/folha/informatica/ult124u506631.shtml.> e <http://www1.folha.uol.com.br/folha/bbc/ult272u532129.shtml.>
} 
informações sobre a estrutura governamental, dados biográficos acerca do Presidente, seus ministros e secretários, e, também, confere alta visibilidade aos programas, notícias, discursos, entrevistas e outras publicações promocionais atinentes ao trabalho do Governo Federal.

Em tal experiência, foram identificados poucos mecanismos voltados para incrementar a aquisição de habilidades políticas. Ou seja, a análise não encontrou elementos suficientes para que se possa afirmar a existência de artifícios direcionados a encorajar o envolvimento político dos cidadãos na discussão ou mesmo na produção de decisões sobre políticas públicas. Por exemplo, nenhum dos líderes do governo agendou encontros em fóruns ou em salas de bate-papo a fim de interagir com os usuários do Portal, algo que, certamente, representaria um avanço no senso de eficácia política dos cidadãos (ALMOND \& VERBA, 1963). Ademais, os cidadãos, ao acessarem este website, não tiveram a oportunidade de rastrear as mensagens eventualmente por eles enviadas, uma vez que a tecnologia adotada pelo Portal da Presidência não contempla este tipo de oportunidade. Por último, aqueles recursos participativos mais avançados encontrados em outras iniciativas (como fóruns públicos, sondagens de opinião e salas de bate-papo) também não foram identificadas (MUSSO, WEARE \& HALE, 2000; FUNG, 2003; JANSSEN \& KIES, 2005; WRIGHT \& STREET, 2007). Os endereços de e-mail e formulários para preenchimento são os únicos mecanismos à disposição daqueles usuários interessados em contatar a Presidência através da internet.

Nesse sentido, a pesquisa conclui, a partir da análise do website da Presidência, que, não obstante o viés de centro-esquerda do governo brasileiro eleito em 2006 ou o discurso oficial a destacar a potencialidade participativa dos media digitais (BRASIL, 2004), pouco tem sido feito a fim de se aumentar as oportunidades de participação política através da internet nesta experiência específica.

Por outro lado, deve-se sublinhar que o Portal da Câmara dos Deputados dá aos cidadãos a possibilidade de conhecer como funciona o Poder Legislativo em âmbito Federal, permitindo, por exemplo, um acompanhamento mais próximo do trabalho dos parlamentares ou dos gastos que os representantes eleitos realizam com o dinheiro público. Uma quantidade considerável de informação voltada para permitir consultas diversas e uma variedade notável de artigos e textos políticos e técnicos também está acessível (MARQUES, 2008).

Isto é, o website da Câmara dos Deputados apresenta um aparato informacional mais diverso se comparado à iniciativa administrada pela Presidência da República. É verdade que o website da Câmara também oferece informação dedicada a promover sua própria imagem pública; no entanto, este Portal também encoraja os cidadãos a fiscalizarem o trabalho realizado pelos parlamentares. Nesse sentido, uma série de dados previamente restritos se encontra, agora, 
disponível para acesso: é possível saber, por exemplo, quanto dinheiro o gabinete de cada deputado gasta, além publicar informações sobre os assessores nomeados em cada um dos escritórios dos 513 representantes da Casa. Outros textos e materiais de aprofundamento a fornir o debate de temas atuais são facilmente acessíveis em seções do site como aquela denominada "Fique por dentro" e "Saiba mais sobre o processo legislativo".

O website da Câmara ainda oferece ao usuário a oportunidade de entrar em contato com todas as seções da instituição por e-mail. A Casa também encoraja a interação ao prover um número de rastreamento para qualquer tipo de mensagem enviada através dos formulários presentes em seu website. A disponibilidade de sondagens de opinião pública, weblogs, salas de bate-papo, fóruns públicos e outros canais interativos (muitos deles, inclusive, contando com o envolvimento direto de determinados parlamentares) complementam o ciclo participativo verificado neste caso (BRAGA, 2007; MARQUES, 2008; MIOLA, 2009; PEREIRA, 2009). Todos estes são fatores que indicam uma abordagem diferenciada desta iniciativa no que concerne ao uso do potencial democrático dos new media.

Mas a que poderia ser atribuída uma diferença tão marcante entre as duas experiências examinadas na pesquisa que dá origem a este artigo? Mesmo sabendo que cada uma destas instituições conta com escopo e responsabilidade muito peculiares em um Estado democrático (o fato de serem ligadas a diferentes poderes, como o Executivo e o Legislativo, provocam o estabelecimento de uma relação distinta com o cidadão), este trabalho investiga os dois casos tendo em conta seus diferentes modos de administrar o uso das novas tecnologias de comunicação. Dito de outro modo, a hipótese aqui defendida é a de que existe um conjunto de fatores que determina os modos como estas duas instituições utilizam os media digitais a fim de aperfeiçoarem a participação em seus âmbitos particulares.

\section{Uma exploração das dificuldades enfrentadas por projetos institucionais de participação digital}

Em diferentes pesquisas que tratam de aspectos diversos atinentes à democracia digital, nota-se certo tom pessimista quanto à maioria das iniciativas levadas à frente por instituições do Estado. Parte significativa das queixas se refere à idéia de que a capacidade interativa dos media digitais não estaria sendo aproveitada de modo adequado por tais entidades (STROMER-GALLEY, 2000; SCHEUFELE \& NISBET, 2002; POLAT, 2005; FERBER, FOLTZ \& PUGLIESE 2003 e 2005; GOMES, 2005). Que razões poderiam estar por trás deste fenômeno, já documentado em um conjunto amplo de pesquisas empíricas? Três pontos principais encetam a discussão. 
Um importante grupo de estudiosos aponta como principal razão para suas conclusões pessimistas a indisposição dos representantes eleitos e das instituições estatais em incrementar seu relacionamento político com os cidadãos. Estes autores sugerem que a ênfase tradicional sobre a representação estrita [uma característica própria das democracias modernas, conforme asseveram David Held (1987) e Bernard Manin (1997)] tende a resistir a mudanças na dinâmica do processo de produção da decisão política. O argumento fundamental destes especialistas é o de que os representantes se sentem desconfortáveis com a idéia de compartilhar poder político com os cidadãos, ainda que em níveis elementares (NOVECK, 2004; STANLEY \& WEARE, 2004; FROOMKIM, 2004; PRATTIPATI, 2003).

Este seria, então, o principal motivo pelo qual um número considerável de projetos institucionais de democracia digital toma os cidadãos apenas como meros clientes inseridos no processo político, em prejuízo de uma parceria mais aprofundada (VINTAR, DECMAN \& KUNSTELJ, 1999). Autores tais como Stanley, Weare e Musso (2004) enfatizam, assim, a necessidade particular de que as autoridades públicas dêem maior consideração à adoção institucional de mecanismos mais aprofundados de participação digital, bem como passem a tomar parte no uso ordinário destes mecanismos, de forma a atrair mais cidadãos a se engajarem politicamente.

Outros estudiosos apontam um segundo foco de resistência e de dificuldades que os projetos institucionais de e-participação precisam enfrentar: os custos de implementação de tais experiências. Enquanto que, de um lado, há uma série de referências a destacar a maior conveniência e os custos mais baixos de participação que incidem sobre os usuários (CHADWICK, 2003; BORGIDA \& STARK, 2004; AALTO-MATTURI, 2005), por outro lado, afirma-se que muitos destes custos são transferidos para as instituições representativas, que, agora, precisam lidar, por exemplo, com um número mais extenso de tarefas e de dados para processar (ARTERTON, 1987; BALNAVES, WALSH \& SHOESMITH, 2004; COGLIANESE, 2005). Este último argumento considera que lidar com uma maior quantidade de mensagens assusta os representantes e seus assessores que se encontram "do outro lado" da tela, já que responder satisfatoriamente a todas as questões endereçadas por meio da comunicação digital requer um grande investimento em equipamentos e na contratação de novos funcionários ${ }^{5}$.

A terceira e última dificuldade é concernente não a um problema político, mas a uma questão técnica. Alguns pesquisadores se dedicam a estudar os meios e

\footnotetext{
${ }^{5}$ Sublinha-se um outro receio peculiar: uma vez que os representantes eleitos ofereçam oportunidades de participação política mais aprofundadas, ele terão de lidar com uma quantidade considerável de questões controversas que podem trazer problemas, por exemplo, às suas imagens públicas, influenciando seus resultados nas urnas (STROMER-GALLEY, 2000).
} 
modos como o desenho e a configuração das ferramentas digitais influenciam o sucesso das iniciativas de e-participação (DAHLBERG, 2001; WRIGHT \& STREET, 2007; FERBER, FOLTZ \& PUGLIESE, 2003 e 2005; STANLEY \& WEARE, 2004). Beth Noveck (2004) critica o fato de que, na maioria dos websites oficiais, os recursos de participação disponíveis são concebidos e formatados não por especialistas familiarizados com as necessidades de uma governança mais democrática, mas, sim, por consultores da área de tecnologia.

"With an eye toward improving efficiency, they [technology consultants] simply "put paper on-line" and digitize the rulemaking process without regard to impact on public engagement. [...] this directs resources away from the interactivity of the technology... and shifts the center of attention from active participation toward passive information gathering ${ }^{\prime \prime}$ (NOVECK, 2004, p. 4-5).

A observação de Noveck é reforçada pelas investigações empíricas conduzidas por Ferber, Foltz e Pugliese (2003 e 2005). Estes autores examinaram os modos de trabalho de consultores em tecnologia responsáveis pelo desenvolvimento e manutenção dos websites de 50 legislaturas em estados norteamericanos. A pesquisa descobriu que a maioria destes profissionais tende a ressaltar os aspectos técnicos dos sites (principalmente seu caráter de funcionalidade e usabilidade), às custas do incremento de valores democráticos, como a transparência. A disponibilidade de vídeos e de informações biográficas sobre os parlamentares foram considerados aspectos "interativos" pelos consultores entrevistados ao longo da pesquisa conduzida por Ferber e sua equipe. Tal constatação implica que, se o propósito fundamental consistir, de fato, em fortalecer o envolvimento político dos cidadãos, é necessário conferir maior atenção aos modos como as ferramentas participativas são configuradas.

Uma vez discutido o pano de fundo teórico que sugere haver dificuldades para o empreendimento de projetos institucionais voltados para fortalecer a participação dos cidadãos através dos media digitais, o trabalho se propõe a examinar de que forma os dois casos selecionados para a amostra da pesquisa empírica refletem tais constrangimentos. Em um primeiro momento, pode parecer estranho ou dissonante comparar os papéis e as atividades políticas desempenhadas pela Presidência, de um lado, e pela Câmara dos Deputados, de

6 Tradução própria: "Com uma perspectiva voltada para o aperfeiçoamento da eficiência, eles, simplesmente, 'transpõem o papel para o online' e digitalizam o processo de elaboração das normas governamentais sem levar em conta o impacto sobre o engajamento público. [...] isto direciona os recursos para longe da interatividade da tecnologia e modifica o centro da atenção para a participação ativa em direção à coleta passiva de informações." 
outro. Por exemplo, a existência de um item chamado "Plenário" não faria sentido no Portal da Presidência”. Não obstante, este trabalho acredita que é possível cotejar as estratégias administrativas e organizacionais destas duas iniciativas no que se refere ao emprego mais ou menos aprofundado dos new media. Em outras palavras, o estudo de aspectos tais como o design, a variedade e a profundidade dos mecanismos participativos identificados nestes websites permite que se descubra elementos importantes acerca dos esforços que tais instituições empreendem a fim de promover a participação política.

\section{Estudos de caso: Méritos, Dificuldades e Desafios}

\section{O Portal da Presidência da República}

A pesquisa empírica revelou indícios de que, no caso do Portal da Presidência, a escassa existência de recursos participativos é causada por certa indisposição política e pelas limitações financeiras que atingem o setor responsável pela manutenção da iniciativa. No que se refere à disposição política, pode-se apontar um conjunto de problemas que abatem a administração do Portal em questão.

De acordo com um relatório publicado pelo Tribunal de Contas da União (TCU) em 2006, duas das principais instituições envolvidas na política nacional de governo eletrônico (o Comitê Executivo do Governo Eletrônico - CEGE, vinculado ao Ministério do Planejamento, Orçamento e Gestão - e a Secretaria de Comunicação Social da Presidência - SECOM) estariam disputando espaço pela autoridade em estabelecer determinadas normas atinentes à política de comunicação digital do país. Por um lado, o CEGE é a entidade federal responsável pelo "formular políticas, estabelecer diretrizes, coordenar e articular as ações de implantação do Governo Eletrônico, voltado para a prestação de serviços e informações ao cidadão" (BRASIL, 2000). Por outro lado, a SECOM tem como uma de suas atribuições fundamentais coordenar o sistema de comunicação que integra ministérios, empresas públicas e outras entidades do Poder Executivo Federal. Assim sendo, a Secretaria de Comunicação da Presidência provê informação política através de diferentes suportes midiáticos e tenta enfatizar os pontos positivos do desempenho governamental.

O primeiro problema identificado pelo Tribunal de Contas da União se refere à sobreposição de papéis dessas duas entidades. Pode-se mencionar, por exemplo,

\footnotetext{
${ }^{7}$ Além disso, é necessário dizer que o caráter supra-partidário da Câmara influencia sua disposição em oferecer recursos participativos.
} 
o website denominado "Rede Governo" - http://www.redegoverno.gov.br/, administrado pelo CEGE - e o website Brasil.gov - http://www.brasil.gov.br/ -, coordenado pela SECOM: ambas iniciativas possuem conteúdos bastante similares, o que, segundo o relatório do TCU, implica um desperdício de recursos públicos (BRASIL, 2006, p. 38).

Um outro problema assinalado pelo Tribunal também se refere à estrutura administrativa do próprio Comitê Gestor de Governo Eletrônico. O TCU enfatiza as dificuldades criadas por um Decreto Presidencial de 2000 que exige a presença, em todas as reuniões do Comitê, do Ministro-Chefe da Casa Civil e de outras autoridades como os secretários-executivos de todos os ministérios do Poder Executivo. Por conta da dificuldade em conciliar a agenda de compromissos de todas essas autoridades, o relatório do Tribunal de Contas da União considera que, dificilmente, o Comitê tem condições de reunir-se em uma periodicidade minimamente adequada. Como resultado desta disposição, as diretrizes elaboradas pelos administradores do governo eletrônico brasileiro não são aplicadas com a agilidade necessária.

Ademais, argumenta o relatório do TCU, no caso de uma resolução do CEGE ser aprovada, ela provavelmente encontrará barreiras para ser implementada na íntegra, uma vez que cada instituição do Executivo Federal conta com diferentes níveis de pessoal, treinamento e equipamentos disponíveis a fim de dar cabo às políticas delineadas. De acordo com o documento do Tribunal:

“... cada órgão implementa ações de acordo com seu tempo disponível, sua evolução e condições tecnológicas, além de suas próprias necessidades e prioridades. [...] Os órgãos com estágio incipiente de desenvolvimento de serviços eletrônicos não contam com apoio da coordenação do Programa para implementar seus projetos de e-gov, conforme opinião manifestada nos grupos focais de gestores de portais. Além disso, esses gestores observaram que as diretrizes do Programa não vêm acompanhadas de recursos práticos para sua implementação" (BRASIL, 2006, p. 23-24).

Esta dificuldade do ponto de vista organizacional revela certa indisposição da instituição em fazer uso dos media digitais a fim de fortalecer a interação política dos cidadãos com o governo. Ou seja, a falta de clareza no que se refere às funções específicas de cada entidade no âmbito da estrutura burocrática que administra os projetos de governo eletrônico; a dificuldade em reunir os representantes de diferentes setores do governo nos encontros do CEGE; a disparidade de condições e de recursos entre as instituições para que estas possam implementar soluções em tecnologia da informação (o que revela carência de investimentos em equipamentos 
e em pessoal); e, finalmente, o baixo nível de interatividade das ferramentas de comunicação disponíveis no website são fatos que fortalecem a idéia de que, no caso da Presidência, o primeiro problema identificado no tópico anterior (ou seja, a indisposição dos representantes em se abrir à participação dos cidadãos) se mostra proeminente. Se os recursos de e-participação fossem, de fato, uma prioridade neste caso, acredita-se que tais problemas não apareceriam de forma tão aguda ${ }^{8}$.

Um outro fenômeno sugere a pouca importância que o governo concede ao aperfeiçoamento da participação dos cidadãos através da internet: as experiências brasileiras mais sofisticadas em tecnologia da informação no âmbito do Estado se referem àqueles sistemas digitais voltados para melhorar a arrecadação fiscal. Como exemplo destas iniciativas, pode-se mencionar o website da Receita Federal ${ }^{9}$ (http://www.receita.fazenda.gov.br/).

Sílvia Ferro, chefe da Seção de internet da Secretaria de Comunicação Social da Presidência da República, admitiu, em entrevista, que os mecanismos ofertados para promover o envolvimento político dos usuários no website aqui estudado não são satisfatórios devido a problemas relacionados à falta de estrutura e de pessoal para administrar recursos interativos (FERRO, 2008). Mais exatamente, Ferro diz que o website da Presidência não poderia oferecer ferramentas de participação mais aprofundadas porque conta com o trabalho de apenas três funcionários para administrar dois websites (o Portal da Presidência e o Brasil.gov); outros três técnicos têm a função de responder a todas as mensagens enviadas pelos usuários por meio destas duas experiências.

Esta descoberta se liga não apenas à primeira dificuldade apontada na seção anterior (a indisposição dos agentes políticos em promover o uso de ferramentas participativas), mas, também, está associada com um segundo aspecto, aquele relacionado aos custos de implementação, operação e manutenção daqueles dispositivos voltados para incrementar o envolvimento político dos cidadãos. Desta forma, uma vez que há um quadro reduzido de funcionários para administrar as ferramentas digitais neste caso, pode parecer muito demandar uma configuração mais aprofundada dos mecanismos de e-participação. No final das contas, há indícios suficientes para se acreditar que a pouca importância dada aos media digitais pela Presidência (pelo menos com respeito às oportunidades de participação) é resultado de uma macropolítica de governo eletrônico.

\footnotetext{
8 O curioso é que os documentos oficiais do governo eletrônico brasileiro defendem a necessidade de que se tome vantagem dos media digitais para se aprimorar a participação política dos cidadãos (BRASIL, 2004a, p. 10).

9 Para um maior estudo acerca deste tema, recomenda-se a leitura de Nazareno et al (2006).
} 


\section{O Portal da Câmara dos Deputados}

Do mesmo modo que no caso anteriormente abordado, é possível identificar determinadas peculiaridades no que se refere à importância que a Câmara confere à participação dos cidadãos através de seu website. Primeiramente, enfatize-se o perfil organizacional do website estudado neste tópico.

Uma comissão especial foi nomeada em 2004 a fim de reformular o Portal e apresentou um relatório denominado "Salto Qualitativo" (BRASIL, 2004b). Este documento representa um importante ponto de mutação no modo como a Câmara dos Deputados passou a oferecer oportunidades para participação política online. De acordo com o relatório:

“... o sítio deve promover a comunicação entre a Câmara dos Deputados e sociedade, permitindo a participação popular e a interatividade com os cidadãos, fortalecendo processos participativos, com a incorporação de recursos de interatividade que estimulem a participação ativa da sociedade..." (BRASIL, 2004b, p. 29).

A criação de um Comitê Gestor do Portal, cujos integrantes são oriundos de diferentes setores da Casa; a rotina de reuniões semanais para se discutir o aperfeiçoamento e administração do website, e a disponibilidade de canais diretos de comunicação com o Comitê refletem o cuidado que a instituição e alguns de seus agentes tiveram com o projeto desde o seu início.

Um planejamento prévio também se mostrou fundamental para configurar a quantidade e a profundidade das ferramentas participativas indicadas anteriormente (fóruns públicos, salas de bate-papo, sondagens etc.). Assim sendo, pode-se afirmar que a primeira dificuldade apontada pela literatura (aquela que destaca a resistência institucional em adotar os dispositivos digitais com o intuito de fortalecer as práticas democráticas) não parece se mostrar relevante no caso em tela.

Porém, esta idéia é apenas parcialmente consistente. Se for possível dizer que o Comitê Gestor se esforçou em redesenhar o website de modo a promover ferramentas de participação mais sofisticadas, o mesmo não se pode afirmar acerca de todos os representantes políticos eleitos que, no final das contas, são aqueles que coordenam o processo de produção da decisão política que tem lugar na Casa. Em outras palavras, o caso da Câmara dos Deputados aponta uma outra nuance não facilmente identificável quando se estudou o Portal da Presidência: é necessário desempenhar um passo extra a fim de convencer um outro conjunto de agentes (os próprios representantes eleitos) acerca da importância de se interagir 
com os cidadãos por meio da comunicação digital. Esta descoberta indica que se deve tornar mais complexa a idéia desenvolvida por alguns dos autores citados logo acima: em determinados casos, a instituição tem funcionários técnicos dispostos a fomentar o desenvolvimento de ferramentas de e-participação, porém, uma parcela dos parlamentares pode resistir em tomar parte ou em decisivamente apoiar iniciativas desta natureza. Durante a pesquisa empírica que deu origem a este artigo, foi apontado que o Comitê Gestor costuma pressionar os deputados a responderem àquelas mensagens enviadas por usuários (BOTELHO \& FERREIRA FILHO, 2007). Assim, deve ser sublinhada a diferença entre a disposição dos técnicos da Casa e de seus agentes políticos eleitos.

De modo a lidar com este problema, o Comitê Gestor adotou um sistema de rastreamento das mensagens enviadas pelos usuários. Tal sistema provê um número único para cada mensagem endereçada através do Portal da Câmara e conta com pelo menos duas vantagens: primeiramente, confere-se aos usuários um maior senso de eficácia política (ALMOND \& VERBA, 1963), uma vez que é fortalecida a crença de que suas mensagens terão maiores chances de obter uma resposta; em segundo lugar, o sistema permite ao Comitê monitorar aqueles deputados que não costumam responder as demandas a eles direcionadas. Assim, uma vez que uma baixa incidência de respostas seja detectada, o Comitê Gestor pergunta aos responsáveis pelos gabinetes parlamentares de que modo se poderia reverter tal situação. Adicionalmente, o website da Câmara periodicamente confere visibilidade positiva aos deputados mais atentos às mensagens enviadas pelos usuários, fornecendo um ranking daqueles mais atenciosos em sua seção de notícias.

Acerca dos custos econômicos para se implementar e administrar os mecanismos de e-participação neste caso, dois dos responsáveis pela coordenação do Portal à época, Cássia Botelho e José Ferreira Filho, afirmaram que há alguns limites em relação à quantidade de técnicos e de profissionais necessários para se desempenhar todas as atividades planejadas pelo Comitê (BOTELHO \& FERREIRA FILHO, 2007). Ferreira Filho disse que o setor por ele coordenado contava, na ocasião, com o trabalho de apenas 16 funcionários dedicados a supervisionar toda a seção técnica do sistema de informação da Casa (ao final de 2007, o website da Câmara tinha mais de 15 mil páginas). Ainda que tenham uma quantidade considerável de atribuições, os entrevistados afirmaram que não costumam enfrentar problemas de orçamento para a manutenção do Portal, o que revela uma atenção especial oferecida pela instituição. Este achado demonstra uma relação bastante próxima entre a disposição política e o apoio financeiro a projetos de eparticipação.

Especificamente sobre a configuração de ferramentas participativas digitais, a pesquisa também apontou que o Comitê Gestor apresenta um cuidado especial 
com a formatação daqueles recursos voltados para promover o envolvimento político online dos usuários. De acordo com Cássia Botelho, uma nova ferramenta é colocada à disposição no Portal apenas depois de uma prévia discussão interna no âmbito do Comitê, que leva em conta, ainda, uma avaliação dos custos humanos e econômicos envolvidos na oferta de um recurso novo (BOTELHO \& FERREIRA FILHO, 2007).

A pesquisa empírica verificou também duas preocupações adicionais no que se refere à administração do website: a primeira considera as limitações quanto aos equipamentos dos usuários e à baixa velocidade de conexão que está disponível a muitos cidadãos; a segunda preocupação se liga à capacidade da equipe gestora do Portal em lidar com todas as demandas que serão endereçadas à Câmara toda vez que um novo recurso é tornado disponível (MARQUES, 2008). Um estudo prévio realizado pelo Comitê permite equacionar os problemas e apontar soluções para estes pontos.

Em suma, pode-se afirmar que o Portal da Câmara dos Deputados tem um bom desempenho quando confrontado com aquelas dificuldades tradicionalmente apontadas por parte relevante da literatura. Se, por um lado, isso é verdade, por outro lado, é possível argumentar acerca de um outro conjunto de dificuldades a ser cuidadosamente examinado para se compreender melhor como a política tradicional influencia as instituições do Estado em seus projetos de adoção de mecanismos de e-participação. Acredita-se (em sintonia com a reivindicação exposta em STREET, 1997; COLEMAN, 1999; AGRE, 2002; SEIFERT \& CHUNG, 2009) que, para se entender a adoção da internet com fins participativos, é necessário examinar a interface entre tecnologia e cultura política. Ao discutir esta questão, pretende-se indicar que o Portal da Câmara ainda tem um longo caminho a percorrer.

\section{Um retorno ao político: política tradicional e as dificuldades impostas aos projetos de participação online}

Nesta última seção, discuto um outro conjunto de fatores a influenciar o caráter de projetos governamentais voltados para fortalecer a participação através da internet. Acredita-se que tais fatores efetivamente apresentam algumas advertências acerca do potencial dos new media para incrementar as práticas democráticas. No entanto, este trabalho defende, ao mesmo tempo, que tais ponderações não devem ser vistas como um meio de se reforçar o pessimismo em relação às tecnologias digitais. Na verdade, o objetivo do tópico é examinar a interface entre e-democracia e algumas das tradicionais observações articuladas por teóricos da Filosofia e da Ciência Política que se empenham em compreender a 
complexidade que envolve as iniciativas de participação planejadas por instituições representativas do Estado.

De acordo com o que foi ilustrado na seção anterior, o primeiro passo para se planejar experiências de participação é obter o comprometimento das instituições representativas. Em segundo lugar, um esforço adicional é necessário para convencer os representantes a considerarem os cidadãos como pares tanto na discussão quanto na formulação de políticas públicas (BOHMAN, 1996; OECD, 2001; LUKENSMEYER \& TORRES, 2006). Estes dois passos são fundamentais, mas não são suficientes para fazer funcionar a engrenagem participativa em âmbito institucional.

Uma outra dificuldade deve ser examinada e tem a ver com o cultivo dos "corações e mentes" dos cidadãos e com o fortalecimento de seu senso de responsabilidade cívica e de sua competência política. Este argumento sublinha que a cultura política e as tradições de engajamento cívico que distinguem as sociedades democráticas são essenciais na determinação do sucesso de uma experiência participativa (PUTNAM, 2000). Em outras palavras, apenas por meio do reforço em sua credibilidade, representantes e instituições políticas podem esperar que os cidadãos se sintam confortáveis e estimulados a tomar parte de modo decisivo no processo político (ALMOND \& VERBA, 1963).

De fato, a maioria das dificuldades e constrangimentos mencionados até agora neste tópico influencia qualquer iniciativa de participação. Especificamente acerca da relação entre tais dificuldades e a comunicação digital, é possível tecer os seguintes comentários: primeiramente, conforme Fountain (2001), Blumler e Coleman (2001), Polat (2005) e Balla e Daniels (2007) concordam, qualquer análise séria dos efeitos políticos dos new media sobre a democracia deve evitar o que se chama de "determinismo tecnológico". O impacto das tecnologias digitais sobre o campo político está sempre intimamente relacionado com fatores culturais ou, como diz :

"When institutions change, it is not because a technology such as the internet descends and, deus ex machina, reorganizes the institution's constitutive order in its own image. Institutions do often change as a result of the opportunities that a new technology makes available, but it is only through the workings of the institution that the dynamics of the change can be found ${ }^{10 "}$ (AGRE, 2002, p. 315).

\footnotetext{
10 Tradução própria: "Quando as instituições mudam, isso não acontece porque uma tecnologia tal como a internet recria e reorganiza, de forma independente, a ordem constitutiva da instituição. As instituições são modificadas como um resultado das oportunidades que uma nova tecnologia torna disponível, mas é apenas por meio dos trabalhos da instituição que dinâmica da mudança pode ser identificada."
} 
Em segundo lugar, deve-se considerar o fato de que nem todos os problemas que afetam o desempenho das democracias requerem soluções que têm a ver com a comunicação digital (e, naturalmente, nem todos os problemas que as democracias enfrentam cotidianamente têm relação específica com a questão da participação política). Dito de modo diferente, os recursos de internet não lidam com todos os déficits democráticos de maneira simétrica: parece ser mais fácil, por exemplo, fortalecer aqueles mecanismos voltados para incrementar a transparência governamental ou para defender direitos individuais do que barrar a atuação de lobistas cujo objetivo, muitas vezes, é praticar a famosa "advocacia administrativa".

Ademais, pode-se afirmar que não apenas os new media oferecem respostas diferentes a algumas dificuldades da democracia, mas que, também, diferentes realidades democráticas requerem soluções distintas para seus problemas típicos. Uma vez que as instituições políticas estejam, efetivamente, dispostas a empregar os mecanismos digitais a fim de incrementar suas práticas democráticas, elas deverão tirar vantagem destes recursos considerando a adequação de cada mecanismo a fim de dar conta dos problemas enfrentados em suas agendas.

No final das contas, estaria este artigo, então, comprometido com a defesa de um determinismo sócio-cultural? Isto é, apresenta-se aqui a noção de tecnologias mediáticas como "entirely subordinate to their development and use in particular sociopolitical, historical, and culturally specific contexts"11 (CHANDLER, 1996, p. 2)? A intenção do trabalho não é reforçar forma alguma de determinismo, mas apenas trazer à luz a idéia de que existe uma retroinfluência entre os new media e a política tradicional. Para ilustrar este argumento, a pesquisa que originou o presente artigo revelou, por exemplo, que, uma vez que as instituições representativas tenham adotado recursos digitais de comunicação, os usuários tenderão a empregar crescentemente tais artifícios e a considerá-los, mesmo, uma parte indivisível do cenário político (MARQUES, 2008).

Isso significa que, se, no futuro, um governo tentar remover as ferramentas democráticas já oferecidas através de seus websites, ele provavelmente encontrará uma resistência notável de cidadãos e de organizações cívicas por conta da inovação cultural introduzida pela disponibilidade destes novos dispositivos. Um exemplo claro deste fenômeno é o Portal da Transparência (http://www.portaltransparencia.gov.br/). Tal experiência resultou em claras modificações em parte das atividades políticas em nível federal, uma vez que permite a qualquer usuário a oportunidade de monitorar os gastos públicos no país (tal ferramentas tem sido usada com razoável sucesso pela imprensa em seu papel de "cão de guarda", por exemplo). Acredita-se que outras investigações são

11 Tradução própria: "inteiramente subordinadas ao seu desenvolvimento e uso em contextos sociais, políticos, históricos e culturalmente específicos". 
necessárias acerca deste tópico, mas a compreensão aqui delineada procura fundamentar a hipótese de que existe uma influência recíproca entre política e tecnologia.

\section{Conclusão}

Muitos especialistas apontam diferentes desafios que os projetos governamentais de e-participação devem enfrentar: indisposição das instituições e dos representantes em compartilhar poder político; resistências por conta dos custos econômicos e políticos de implementação de ferramentas de e-democracia; configuração inadequada dos recursos participativos disponíveis. O estudo apresentado neste artigo procurou examinar como estas dificuldades são refletidas em dois casos brasileiros. Especificamente, foram investigadas as ferramentas participativas disponíveis nos portais da Presidência da República e da Câmara dos Deputados.

De acordo com o que demonstrou a pesquisa empírica, o Portal da Presidência enfatiza a construção de imagens públicas positivas de seus agentes políticos, obedecendo a uma provisão de informação política do tipo top-down. Este caso chama a atenção devido a problemas em suas práticas de administração e por causa da carência de recursos adequados para se envolver os usuários no processo de discussão dos negócios públicos. Claramente, assim, as prioridades do governo brasileiro (nomeadamente do Poder Executivo Federal) não são direcionadas, no caso do Portal da Presidência, ao incremento das práticas participativas.

A Câmara dos Deputados, por sua vez, apresentou uma disposição diferenciada ao tornar outros recursos participativos presentes em seu website. Desde que o relatório "Salto Qualitativo" foi apresentado, a Casa se destaca por seu comprometimento em apoiar a iniciativa do ponto de vista financeiro e político. Uma quantidade considerável de mecanismos de participação (fóruns públicos, salas de bate-papo e sondagens de opinião) foi encontrada nesta experiência. No entanto, ainda é algo importante levar em conta a disposição dos representantes em estabelecer uma conversação com os usuários. Assim, já que cada iniciativa mantém uma relação particular com as ferramentas de e-participação tecnicamente disponíveis, os desafios e dificuldades enfrentados pelos projetos de democracia digital também se encontram em diferentes níveis. Por esta razão, defende-se que a investigação conduzida e apresentada neste artigo foi além daquelas três alegações apresentadas no início do trabalho.

Por último, este artigo esteve engajado na tarefa de reforçar a idéia de que se deve evitar qualquer tipo de determinismo, seja ele orientado tecnologica ou culturalmente. Uma abordagem satisfatória do tema aqui investigado considera integralmente a influência recíproca entre as ferramentas digitais e as práticas 
políticas (incluindo as práticas concernentes à participação). Em outras palavras, defende-se que promover a participação dos usuários requer mais do que a simples oferta de dispositivos de e-participação: o fortalecimento da participação política é uma tarefa complexa e requer a consideração de uma variedade de atividades, circunstâncias, agências e atores políticos. A cultura cívica, a profundidade dos problemas democráticos e as peculiaridades de cada sociedade são elementos fundamentais que influenciam os padrões de envolvimento dos cidadãos com as instituições do Estado.

\section{Referências Bibliográficas}

AALTO-MATTURI, S. "The internet: The new workers' hall the internet and new opportunities for the Finnish trade union movement". Working USA, Vol. 8, No. 4., p. 469. 481, 2005.

ABERS, R. N. Inventing Local Democracy: Grassroots Politics in Brazil. Boulder: Lynne Rienner Publishers, 2001.

AGRE, P. "Real-Time Politics: The Internet and the Political Process". The Information Society, vol. 18, p. 311-331, 2002.

ALMOND, G. \& VERBA, S. The civic culture: political attitudes and democracy in five nations, Princeton: Princeton University Press, 1963.

ARTERTON, C. Teledemocracy: Can Technology Protect Democracy? Newbury Park: Sage, 1987.

AVRITZER, L. Participatory Institutions in Democratic Brazil. Baltimore: John Hopkins University Press, 2009.

BAIOCCHI, G. Militants and Citizens: The Politics of Participatory Democracy in Porto Alegre. Stanford: Stanford University Press, 2005.

BALLA, S. \& DANIELS, B. "Information Technology and Public Commenting on Agency Regulations". Regulations \& Governance, 46, p. 46-67, 2007.

BALNAVES, M., WALSH, L., SHOESMITH, B. 'Participatory Technologies: The Use of the Internet in Civic Participation and Democratic Processes'. A paper presented in the Australian Governance Conference. Centre for Public Policy, University of Melbourne Victoria, 14th and 15th April, 2004. 
BENNETT, L. W. "Communicating Global Activism". Information, Communication \& Society, 6 (2), p. 143-168, 2003.

BLUMLER, J. \& COLEMAN, S. "Realising Democracy Online: A Civic Commons in Cyberspace" [Online], IPPR/Citizens, 2001. Disponível em:

$<w w w . c i t i z e n s o n l i n e . o r g . u k / s i t e / m e d i a / d o c u m e n t s / 925 \_R e a l i s i n g \% 20 D e m o c r a c y \%$ 200nline.pdf> Acesso em: [maio 2010]

BOBBIO, N. Left and Right: The Significance of a Political Distinction, trans. \& intro, by A. Cameron. Chicago: University of Chicago Press, 1996.

BOHMAN, J. Public Deliberation: Pluralism, Complexity and Democracy. Cambridge: MIT Press, 1996.

. "Expanding dialogue: The Internet, the public sphere and prospects for transnational democracy." The Sociological Review, 52(s1), p. 131-155. 2004.

BORGIDA, E. \& STARK, E. N. "New media and Politics: Some Insights From Social and Political Psychology". American Behavioral Scientist, 48, p. 467.478, 2004.

BOTELHO, C.; FERREIRA FILHO, J. A. Entrevista ao pesquisador, Brasília, 2007.

BRAGA, S. O papel das TICs na institucionalização das democracias: Um estudo sobre a informatização dos órgãos legislativos na América do Sul com destaque para o Brasil, CEDI/Plenarium, Brasília, 2007.

BRASIL. Decreto de 18 de outubro de 2000. Cria, no âmbito do Conselho de Governo, o Comitê Executivo do Governo Eletrônico, e dá outras providências. D.O.U., Brasília, DF, 2000.

BRASIL. Comitê Executivo do Governo Eletrônico. Oficinas de Planejamento Estratégico: relatório consolidado. Brasília, 2004. Disponível em: <http://www.governoeletronico.gov.br/governoeletronico/index.html> Acesso em: [abr. 2008].

BRASIL. Relatório Do Salto Qualitativo Do Sítio Da Câmara Dos Deputados, 2004b [Online] Disponível em:

<http://www2.camara.gov.br/sobreoportal/gestaoportal/relatorios/relatorio. grupotrabalho-aprimoramento-sitio.pdf> Acesso em: [jan. 2008]

BRASIL. Relatório Avaliação do Programa Governo Eletrônico, 2006 [Online] Disponível em:

<http://www2.tcu.gov.br/pls/portal/url/ITEM/222719124DCC6236E040010A7000 5F69> Acesso em: [mar. 2008]. 
BUCY, E. P. \& GREGSON, K. S. "Media participation: A legitimizing mechanism of mass democracy". New media \& Society, London, 3 (3), p. 357-380, 2000.

CARLSON, T. \& DJUPSUND, G. "Old Wine in New Bottles? The 1999 Finnish Election Campaign on the Internet". Harvard International Journal of Press Politics, Harvard, 6 (1), p. 68-87, 2001.

CHADWICK, A. "Bringing E-Democracy Back In: Why it Matters for Future Research on E-Governance", Social Science Computer Review, 21, p. 443.455, 2003.

CHANDLER, D. "Shaping and Being Shaped: Engaging with Media". Computer mediated Communication, Magazine, 1 February, 1996.

COGLIANESE, C. "The Internet and Citizen Participation in Rulemaking",. I/S: J. L. \& Pol. Info. Soc, 1: 33-57, 2005.

COLEMAN, S. "Can the new media Invigorate Democracy?". Political Quarterly, 70(2), p.16-22, 2009.

COLEMAN, S. \& GØTZE, J. Bowling Together: Online Public Engagement in Policy Deliberation, London: Hansard Society, 2001.

COLEMAN, S. \& SPILLER, J. "Exploring New media Effects on Representative Democracy". The Journal of Legislative Studies, Vol.9, No.3, p. 1-16, 2003.

CREIGHTON, J. L. The Public Participation Handbook: Making Better Decisions Through Citizen Involvement. San Fransisco: Jossey-Bass, 2005.

DAHLBERG, L. "Extending the Public Sphere through Cyberspace: The Case of Minnesota E-Democracy", First Monday, 6(3) [Online] Disponível em: <http://www.firstmonday.dk/issues/issue6_3/dahlberg/index.html>.

"The corporate colonization of online attention and the marginalization of critical communication?". Journal of Communication Inquiry, lowa 29(2): 160-180, 2001.

. "Rethinking the fragmentation of the cyberpublic: from consensus to contestation". New media \& Society, Illinois, 9, p. 827-847, 2007.

DEAN, J. "Why the Net is not a Public Sphere". Constellations, 10 (1), p. 95.112, 2003

DELLI CARPINI, M. "Gen.com: Youth, Civic Engagement, and the New Information Environment". Political Communication, 17: 341-349, 2000.

DREYFUS, H. On the Internet. New York: Routledge, 2001. 
FERBER, P.; FOLTZ, F. \& PUGLIESE, R. "The Politics of State Legislature Web Sites: Making E-Government More Participatory". Bulletin of Science, Technology \& Society, Vol. 23, 157-167, 2001.

"The Internet and Public Participation: State Legislature Web Sites and the Many Definitions of Interactivity". Bulletin of Science, Technology \& Society, Vol. 25, p. 85.93, 2005.

FERRO, S. Entrevista por e-mail, Brasília, Brasil, 2008.

FOUNTAIN, J. Building the Virtual State: Information Technology and Institutional Change. Washington: Brookings Institution Press, 2001

FRANKLIN, K. \& LOWRY, C. "Computer-mediated focus group sessions: naturalistic inquiry in a networked environment". Qualitative Research, v1 i2, p. 169-184, 2001.

FROOMKIN, A. M. "Technologies for Democracy". In: SHANE, P. (ed.). Democracy Online: The Prospects for Political Renewal Through the Internet. New York: Routledge, 2004.

FUNG, A. "Deliberation Where You Least Expect It: Citizen Participation in Government". Connections, Fall, p. 30-33, 2003.

FUNG, A. \& WRIGHT, E. O. "Deepening Democracy: Innovations in Empowered Participatory Governance", Politics and Society, 29:1, p. 5-41, 2001.

GIBSON, R. "Elections Online: Assessing Internet Voting in Light of the Arizona Democratic Primary." Political Studies Quarterly, 116(4): p. 561-583, 2001.

GIBSON, R. K.; LUSOLI, W. \& WARD, S. "Online Participation in the UK: Testing a 'Contextualised' Model of Internet Effects". British Journal of Politics and International Relations, 7(4), p. 561-583, 2005.

GOMES, W. "A democracia digital e o problema da participação civil na decisão política". Revista Fronteiras, v. VIII, n. 3, p. 214-222, 2005.

GUEORGUIEVA, V. "Voters, MySpace, and YouTube: The impact of alternative communication channels on the 2006 election cycle and beyond". Social Science Computer Review, 26(3), p. 288-300, 2007.

GUNKEL, D. J. "Second thoughts: toward a critique of the digital divide". New Media \& Society, 5(4), p.499-522, 2003.

HELD, D. Models of democracy. Stanford: Stanford University Press, 1987. 
HOOGHE, M. \& TEEPE, W. Party Profiles on the Web. An Analysis of the Logfiles of Non-Partisan Interactive Political Internet Sites in the 2003 and 2004 Election Campaigns in Belgium'. [Online] Disponível em:

<http://www.allacademic.com/meta/p41662_index.html> Acesso em: [maio 2010]

JANSSEN, D. \& KIES, R. "Online Forums and Deliberative Democracy". Acta Politica, n. 40. p. 317-335, 2005.

KECK, M. E. The Workers' Party and Democratization in Brazil. Yale University Press, New Haven, 1995.

LUKENSMEYER, C. J. \& TORRES, L. H. Public Deliberation: A Manager's Guide to Citizen Engagement, [Online] IBM Center for The Business of Government, 2006, Disponível em: <http://www.businessofgovernment.org.> Acesso em: [08 jul. 2010]

MANIN, B. Principles of Representative Government. Cambridge: Cambridge University Press, 1997.

MARCHE, S. \& MCNIVEN, J. "E-government and e-governance: The future isn't what it used to be". Canadian Journal of Administrative Sciences, 20, 1; ABI/INFORM Global. pg. 74, 2003.

MARMURA, S. "A net advantage? The internet, grassroots activism and American Middle-Eastern policy". New Media \& Society, 10, p. 247-271, 2008.

MARQUES, F. P. J. A. Participação política e internet: meios e oportunidades digitais de participação civil na democracia contemporânea, com um estudo do caso brasileiro, Salvador, 498 fls, Tese (doutorado). Faculdade de Comunicação, Universidade Federal da Bahia, 2008.

MEDAGLIA, R. 'The Diffusion of eParticipation in English and Italian Local Government', in Anders, A.; Hedström, K.; Rose, J.; Grönlund, Å., Understanding eParticipation: Contemporary PhD eParticipation Research in Europe, Örebro University Library, p. 131-151, 2007.

MIOLA, E. Deliberação Online em Ambientes Institucionais: Um Estudo do Fórum de Discussão do Portal da Câmara dos Deputados. Contemporanea (UFBA), v. 7, p. 1 . 24, 2009.

MITRA, A. "Marginal voices in Cyberspace". New Media \& Society, 3 (1), p. 29-48, 2001.

MUSSO, J.; WEARE, C. \& HALE, M. "Designing web technologies for local governance reform: Good management or good democracy?". Political Communication, 17 (1), 1-19, 2000. 
NAZARENO, C.; VELLOSO, E.; MENDES, F. \& PAZ, J.S. Tecnologias da informação e sociedade: o panorama brasileiro. Câmara dos Deputados, Brasília, 2006.

NETCHAEVA, I. "E-government and e-democracy: a comparison of opportunities in the north and south". Gazette: The International Journal for Communication Studies, 64(5), 467-477, 2002.

NORRIS, P. Digital Divide: Civic Engagement, Information: Poverty and the Internet in Democratic Societies. New York: Cambridge University Press, 2001.

NOVECK, B. S. "The future of citizen Participation in the Electronic State: Modeling Communicative Action in E-Rulemaking Practice". Proceedings of the 9th International Working Conference on the Language-Action Perspective on Communication Modelling, New Brunswick: Rutgers University, The State University of New Jersey, 2004.

OECD. Citizens as partners: OECD Handbook on Information, Consultation and Public Participation in Policy-Making, Paris: Organization for Economic Cooperation and Development (OECD), 2001.

OECD. Promise and Problems of E-Democracy: Challenges of Online Citizen Engagement, Paris: Organization for Economic Cooperation and Development (OECD), 2003.

PEREIRA, S. Estado, democracia e internet: requisitos democráticos e dimensões analíticas para a interface digital do Estado, Salvador, $425 \mathrm{fls}$, (Tese de Doutorado), Universidade Federal da Bahia, 2009.

POLAT, K. R. "The Internet and Political Participation: Exploring the Explanatory Links". European Journal of Communication, 20 (4): 435-459, 2005.

PRATTIPATI, S. "Adoption of e-governance: differences between countries in the use of online government services". Journal of American Academy of Business, Cambridge, vol. 3, no. 1/2, p. 386-91, 2003.

PUTNAM, R. Bowling Alone: The Collapse and Revival of American Community. New York: Simon \& Schuster, 2000.

SALTER, L. "Democarcy, New Social Movements and the Internet. A Habermasian Analysis". In: MCCAUGHEY, M; AYERS, M. D. (eds.) Cyberactivism. Online Activism in Theory and Practice, New York: Routledge, p. 117-144, 2003.

"Structure and Forms of Use: A contribution to understanding the 'effects' of the Internet on deliberative democracy". Information, Communication \& Society, Vol. 7, No. 2, p. 185-206, 2004. 
SCHEUFELE, D. \& NISBET, M. "Being a citizen online: New opportunities and dead ends". Harvard International Journal of Press/Politics, 7 (3), p. 55-75, 2002.

SCHUSSMAN, A. \& EARL, J. "From Barricades to Firewalls? Strategic Voting and Social Movement Leadership in the Internet Age". Sociological Inquiry, 74 (4), p. 439-463, 2004.

SEIFERT, J. W. \& CHUNG, J. "Using E-Government to Reinforce Government-Citizen Relationships". Social Science Computer Review, 27 (2), p. 3.23, 2009.

SHULMAN, S. W. "The Internet Still Might (but Probably Won't) Change Everything". I/S: A Journal of Law and Policy, 1(1): 111-145, 2004.

STANLEY, J. W. \& WEARE, C. "The Effects of Internet Use on Political Participation: Evidence from an Agency Online Discussion Forum". Administration \& Society, 36, 503-527, 2004.

STANLEY, J. W.; WEARE, C. \& MUSSO, J. "Participation, Deliberative Democracy, and the Internet: Lessons from a National Forum on Commercial Vehicle Safety". In: SHANE, P. (ed.) Democracy Online: The Prospects for Political Renewal Through the Internet. New York: Routledge, 2004.

STREET, J. "Remote Control? Politics, Technology and 'Electronic Democracy". European Journal of Communication, 12, p. 27.42, 1997.

STROMER-GALLEY, J. "Online Interaction and Why Candidates Avoid It". Journal of Communication, 50(4): 111-132, 2000.

SUNSTEIN, C. Republic.com. Princeton: Princeton University Press, 2001.

THORSEN, E. "Journalistic objectivity redefined? Wikinews and the neutral point of view". New Media \& Society, 10, p. 935-954, 2008.

UNITED NATIONS. UN Global E-government Readiness Report 2005: From E. government to E-inclusion, 2005.

UNITED NATIONS. E-Government Survey. [Online] Disponível em: <http://www.unpan.org/egovkb/global_reports/08report.htm> Acessado em : [abr. 2008].

VERBA, S.; BRADY, H. \& SCHOLZMAN, K. Voice and Equality: Civic Volunteerism in American Politics. Cambridge: Harvard University Press, 1995.

VINTAR, M.; DECMAN, M. \& KUNSTELJ, M. "Telematics in the service of democracy: the Slovenian parliament and other Slovenian public institutions on the Internet". Parliament Affairs, 52: 451-463, 1999. 
WAMPLER, B. "When does participatory democracy deepen democracy? Lessons from Brazil”. Comparative Politics, v. 14, n 1 , oct., 2008.

WAMPLER, B. \& AVRITZER, L. "The spread of Participatory Democracy in Brazil: From Radical Democracy to Participatory Good Government". Journal of Latin American Urban Studies, Fall, 7: 37-52, 2005.

WRIGHT, S. \& STREET, J. "Democracy, deliberation and design: the case of online discussion forums". New Media \& Society, 9, p. 849-869, 2007.

WOLTON, D. E depois da Internet? Para uma teoria crítica dos novos médias. Algés, Portugal: Difel, 2001.

Francisco Paulo Jamil Almeida Marques - marquesjamil@yahoo.com.br

Recebido para publicação em março de 2009. Aprovado para publicação em outubro de 2009. 